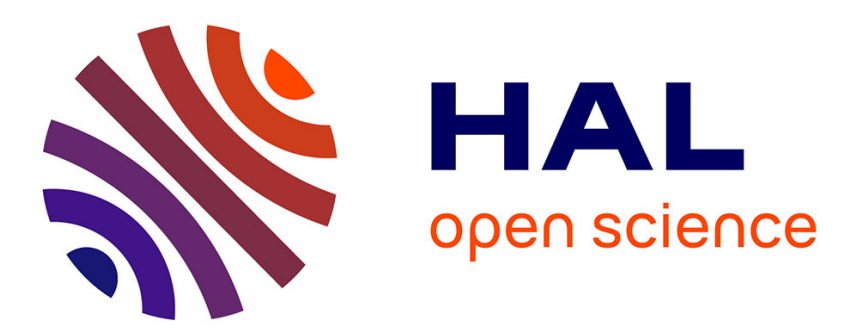

\title{
Cytokine mRNA profiles in pigs exposed prenatally and postnatally to Schistosoma japonicum
}

Michala Techau, Maria Johansen, Bent Aasted, Peter Lind, Niel Ornbjerg, Isabelle P. Oswald

\section{To cite this version:}

Michala Techau, Maria Johansen, Bent Aasted, Peter Lind, Niel Ornbjerg, et al.. Cytokine mRNA profiles in pigs exposed prenatally and postnatally to Schistosoma japonicum. Veterinary Research, 2007, 38 (1), pp.25-36. 10.1051/vetres:2006042 . hal-00903064

\section{HAL Id: hal-00903064 \\ https://hal.science/hal-00903064}

Submitted on 1 Jan 2007

HAL is a multi-disciplinary open access archive for the deposit and dissemination of scientific research documents, whether they are published or not. The documents may come from teaching and research institutions in France or abroad, or from public or private research centers.
L'archive ouverte pluridisciplinaire HAL, est destinée au dépôt et à la diffusion de documents scientifiques de niveau recherche, publiés ou non, émanant des établissements d'enseignement et de recherche français ou étrangers, des laboratoires publics ou privés.

$$
\text { Copyright }
$$




\title{
Cytokine mRNA profiles in pigs exposed prenatally and postnatally to Schistosoma japonicum
}

\author{
Michala E. TeCHAU ${ }^{\mathrm{a}, \mathrm{b}}$, Maria V. JOHANSEN ${ }^{\mathrm{a}}$, Bent AASTED $^{\mathrm{c}}$, \\ Peter LIND ${ }^{\mathrm{d}}$, Niel ORNBJERG ${ }^{\mathrm{a}}$, Isabelle P. OSWALD ${ }^{\mathrm{e} *}$ \\ a DBL - Institute for Health Research and Development, Jaegersborg Allé 1D, \\ 2920 Charlottenlund, Denmark \\ ${ }^{\mathrm{b}}$ Danish Centre for Experimental Parasitology, Dyrlaegevej 100, 1870 Frederiksberg C, Denmark \\ ${ }^{\mathrm{c}}$ Department of Veterinary Microbiology, The Royal Veterinary and Agricultural University, \\ Stigboejlen 7, 1870 Frederiksberg C, Denmark \\ ${ }^{\mathrm{d}}$ Department of Immunology and Biochemistry, Danish Veterinary Institute 27 Bülowsvej, \\ 1790 Copenhagen V, Denmark \\ ${ }^{\mathrm{e}}$ INRA, Laboratoire de Pharmacologie-Toxicologie, 180 Chemin de Tournefeuille, BP 3, \\ 31931 Toulouse Cedex 9, France
}

(Received 30 January 2006; accepted 12 July 2006)

\begin{abstract}
The pig is a natural host for Schistosoma japonicum and a useful animal model of human infection. The aim of the present study was to assess the differences between the cytokine profiles in prenatally or postnatally $S$. japonicum exposed pigs. Seven prenatally exposed pigs, 7 postnatally exposed pigs and 4 uninfected control pigs were compared 27 weeks post exposure. Variables included worm burdens, tissue egg counts, liver pathology and mRNA levels of IL-2, IL-4, IL-10, IL-12, TNF- $\alpha$, TGF- $\beta 1$ and IFN- $\gamma$ in the liver and the caecum, assessed by RT-PCR. Infection intensity and level of septal fibrosis were significantly higher in the postnatal group compared to the prenatal group $(P<0.05)$. A significant increase of IL-4 $(P<0.01)$, IL-10 $(P<0.01)$, IL-12 $(P<0.01)$ and TNF- $\alpha(P<0.05)$ mRNA level was also observed in the caecum of prenatally infected animals compared to the control group $(P<0.01)$. The prenatal group showed higher levels of TGF- $\beta 1$ in the liver compared with the postnatally infected group $(P<0.05)$ and the control group $(P<0.01)$. This suppressive immune response correlated with previously reported low hepatic pathogenesis in prenatally exposed pigs.
\end{abstract}

swine / Schistosoma japonicum / cytokine / prenatal infection / postnatal infection

\section{INTRODUCTION}

Schistosomiasis remains one of the most prevalent infections with more than 200 million people infected worldwide. The disease constitutes a major public health problem in sub-Saharan Africa, re-

* Corresponding author: ioswald@toulouse.inra.fr gions of South America, the People's Republic of China, the Philippines and in minor endemic foci in other Southeast Asian countries [27,37]. Thus, there is still a critical need for a further understanding of the immune responses elicited during infection, in order to generate insight into plausible mechanisms of immune regulation and treatment strategies [42]. 
In chronic infections with Schistosoma mansoni and S. japonicum, parasite development and granuloma formation is believed to be a T-helper (Th) lymphocyte dependent process $[11,24]$. In experimental murine schistosome infections, it was originally thought that a Th2 response, involved in the development of chronic infection, was the main cause of pathology, whereas a Th1 response participated in protection against the infection [9]. However, more recent studies suggest that the situation is more complicated, showing that schistosome infections in mice with reduced type 2 responsiveness lead to a more severe pathological outcome than in mice capable of mounting type 2 responses [14]. In agreement with the more recent studies, immuno-epidemiological studies of human populations in endemic areas have revealed a positive correlation between high, specific immunoglobulin (Ig) E levels, eosinophilia, interleukin (IL)-5 levels and resistance to reinfection after treatment $[30,48]$. However, high levels of gamma interferon (IFN- $\gamma$ ) and tumor necrosis factor (TNF) together with lower levels of IL-5 seem to be associated with hepatosplenic disease [33]. These results support a beneficial role of $\mathrm{Th} 2$ responses in both experimental murine infections and human schistosomiasis.

The current understanding of the immunological basis of schistosomiasis is based mainly on results obtained using murine models [7,39]. There are however, problems in extrapolating results from this unnatural host to humans, especially with regards to granuloma induced fibrosis formation in schistosomiasis patients $[2,13]$. The pig is a natural host for $S$. japonicum [8] and experimental S. japonicum infection has been readily established in Danish Landrace/Yorkshire/Duroc crossbred sows, causing pathogenesis similar to that described in humans, with the most severely affected organs being the intestine and the liver [17]. Willingham et al. [45] showed that $S$. japonicum readily establishes in the pig fetus if the sow is infected during mid to late pregnancy. Interestingly, prenatally exposed pigs were later shown to develop less severe hepatic pathology, compared to challenge control animals, when given a challenge infection [22]. Johansen and Ørnbjerg [23] further showed that treatment with praziquantel, previously reported to give a $100 \%$ cure rate [20], did not cure the prenatal infection and that a challenge infection was readily established in these pigs. These results indicate that pigs might develop partial tolerance towards $S$. japonicum after infection in utero.

The prenatal S. japonicum model is well established in terms of parasitological and pathological effects of the infection [45], but knowledge on induced production of immune mediators is very scarce [41]. A deeper understanding of the cytokine responses induced in prenatally and postnatally exposed pigs, might reveal important differences, reflecting which factors are likely to be involved in immunopathology, given that the pathological outcome of disease is less severe in prenatal infections. Here the mRNA expression levels for 7 different cytokines were measured, in order to investigate the cytokine profiles in prenatally versus postnatally $S$. japonicum exposed pigs.

\section{MATERIALS AND METHODS}

\subsection{Parasites}

Schistosoma japonicum of the Anhui strain [21], were maintained by laboratory passage in Oncomelania hupensis snails and female NMRI mice housed at DBL Institute for Health Research and Development. Cercariae were harvested as previously described [31]. 


\subsection{Animals and experimental design}

Six pathogen-free and helminth-naive Danish Landrace/Yorkshire/Duroc crossbreed sows were used in this experiment. Ten weeks post-insemination, 3 of the sows were infected by intramuscular injection of 10000 S. japonicum cercariae [44]. Seven piglets born from the infected sows were removed immediately after delivery, and received colostrum and milk from an uninfected sow, to ensure that the immunity of the sows had no influence on the immune responses mounted in the prenatally exposed piglets. Among piglets born from uninfected control sows, seven were infected intramuscularly with 1000 cercariae 9 weeks post delivery, while 4 piglets remained as uninfected controls and received an injection of suspension medium as previously described [41]. All animals were housed at Sjaelland III and treated in accordance with protocols approved by the animal ethics committee of Denmark.

\subsection{Parasitological techniques}

At 27 weeks post-infection (i.e. at 21 and 36 weeks of age for the prenatally and postnatally exposed animals respectively), all the pigs were perfused as previously described [4]. Briefly, pigs were killed by an intravenously injected overdose of pentobarbital $(30 \mathrm{mg} / \mathrm{kg})$. Heparin sulfate $(5000 \mathrm{IU})$ was also injected intravenously. One central longitudinal cut was performed from the sternum to the lower abdomen and selective perfusion of the portal hepatic system and the intestinal mesenteric system was achieved by clamping the vessels supplying blood to other organs and hind legs. The perfusion tube was inserted into the aorta and sodium citrate containing saline was pumped through the portal and mesenteric vessels and collected at the punctured portal vein. The perfusate was sieved and worms were collected [4]. Adult S. japonicum worms were counted and classified according to sex and maturity. After perfusion, the intestinal tract of each pig was examined for residual worms, and the caecal mucosae were scraped for tissue egg counts. The number of eggs in the faeces, liver and caecum was determined as previously described [41]. Liver fibrosis was examined and scored as none $=0$, mild $=1$, moderate $=2$, or severe $=3$ depending on the number of worm nodules, lesions and levels of interlobular connective tissue related to fibrosis [21].

\subsection{Determination of cytokine mRNA expression by semi-quantitative RT-PCR}

Tissue samples were taken at the autopsy of the animals from lesion sites in the liver and the caecum. They were immediately preserved in Trizol Reagent (GibcoBRL, Life Technologies, Germany) and homogenized on ice using a Cat homogenizer. Total RNA was extracted as recommended by the manufacturer and quantitated by spectrophotometry. Semi-quantitative determination of IL-2, IL-4, IL-10, IL-12, TNF- $\alpha$, TGF$\beta 1$ and IFN- $\gamma$ levels was carried out using RT-PCR as previously described, using cyclophilin as the housekeeping gene control [34]. Briefly, mRNA was reverse transcribed with Moloney leukaemia virus reverse transcriptase (Promega, Charbonnières, France) and amplified with DNA Taq polymerase enzyme (Invitrogen, Life Technology, Cergy-Pontoise, France). The primer sequences, number of cycles and the annealing temperature used for PCR amplification of each cytokine and cyclophilin are summarized in Table I. Semiquantitative analysis of PCR products was done by hybridization of ${ }^{32} \mathrm{P}$-labelled specific oligonucleotide probes to the PCR products, which were immobilized on nitrocellulose membranes by dot blotting as previously described $[10,35]$. The 
M.E. Techau et al.

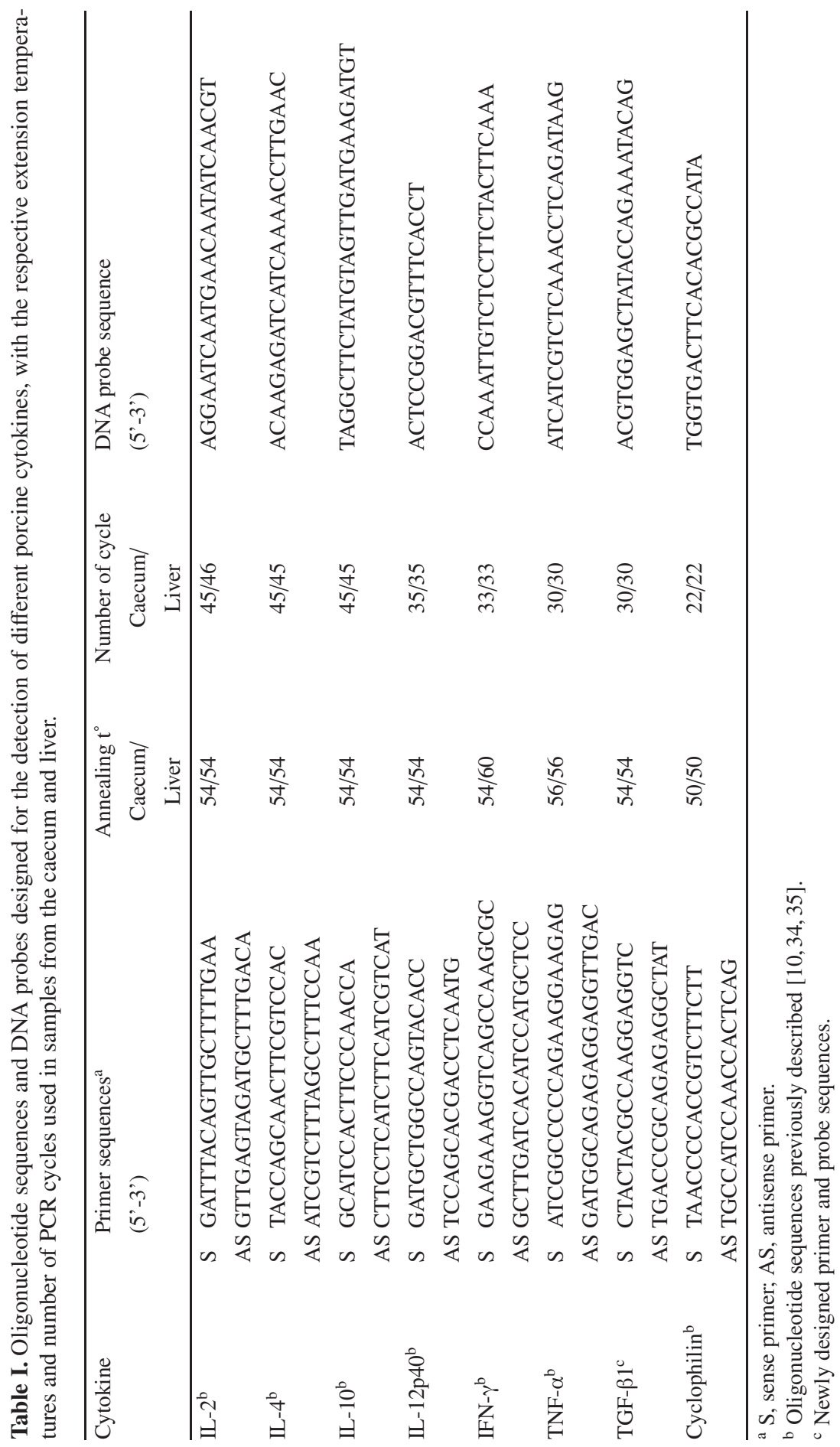


sequence of the DNA probes used for hybridization to the different cytokines is listed in Table I. The relative amount of each product was determined by measuring radioactivity with a Phosphor Imager (Molecular Dynamics, Sunny-vale, CA, USA). For each cytokine, the amount of RT-PCR product was normalized to the values obtained for cyclophilin, as an internal standard for each sample.

\subsection{Statistical Analysis}

Data from individual pigs are presented as the group mean \pm standard deviation. Statistical differences between group means for worm burdens, fecal and liver egg counts and cytokine expression levels were determined using One-way analysis of variance, and post hoc comparisons were done with the Scheffe range test. Prior to analysis, caecum and liver egg counts were transformed to $\log _{10}$. Correlations between parasitological variables were assessed by using the Pearson correlation test. The ranked degree of liver gross pathology was compared between the two groups using the Kruskal-Wallis test and Mann-Whitney U-test. All analyses were done using the program Statistical Package for Social Sciences ${ }^{1}$ (SPSS) version 11.0. Values of $P<0.05$ were considered significant.

\section{RESULTS}

\subsection{Level of parasitic infection}

Piglets were exposed prenatally or postnatally to $S$. japonicum infection. By examination of faecal egg excretion, infection was demonstrated in 5 of the 7 prenatally exposed piglets and in 6 of the 7 postnatally exposed piglets. The total number

\footnotetext{
${ }^{1}$ www.SPSS.com.
}

of worms was significantly higher in the postnatally exposed group in comparison to the prenatally exposed group $(P<0.05)$ (Tab. II).

Faecal egg excretion remained low throughout the experiment, and due to high variation within each group, there was no significant difference at any time between the two groups (data not shown). At autopsy, the number of eggs in the liver was higher in the postnatally exposed group $(P<0.01)$. There was no difference in the level of portal fibrosis between the two groups, but a significantly higher degree of septal fibrosis was seen in the postnatally exposed group compared to the prenatally exposed group $(P<0.05)$ (Tab. II).

\subsection{Cytokine mRNA expression levels in liver and caecum samples}

Twenty-seven weeks post infection, liver and caecum samples were collected for investigation of IL-2, IL-4, IL-10, IL12 , IFN- $\gamma$, TNF- $\alpha$ and TGF- $\beta 1$ mRNA expression levels (Figs. 1 and 2). In the liver, the TGF- $\beta 1$ mRNA expression level was significantly higher in the prenatally exposed group compared to the levels observed in both the control group $(P<$ $0.01)$ and the postnatally exposed group $(P<0.05)$. Furthermore, significantly higher levels of TNF- $\alpha$ and IL-2 mRNA were seen in the postnatally exposed group compared to the control $(P<0.05)$, and a tendency towards higher IFN- $\gamma$ levels was also observed in the postnatally exposed group.

In the caecum IL-4, IL-10, IL-12 and TNF- $\alpha$ levels were significantly increased in the prenatally exposed group compared to the control group (for IL-4, IL-10, IL-12 $P<0.01$, and for TNF- $\alpha, P<0.05$ ), while a tendency to higher TGF- $\beta 1$ levels was observed. The levels of IFN- $\gamma$ and TNF$\alpha$ in the postnatally exposed group were 


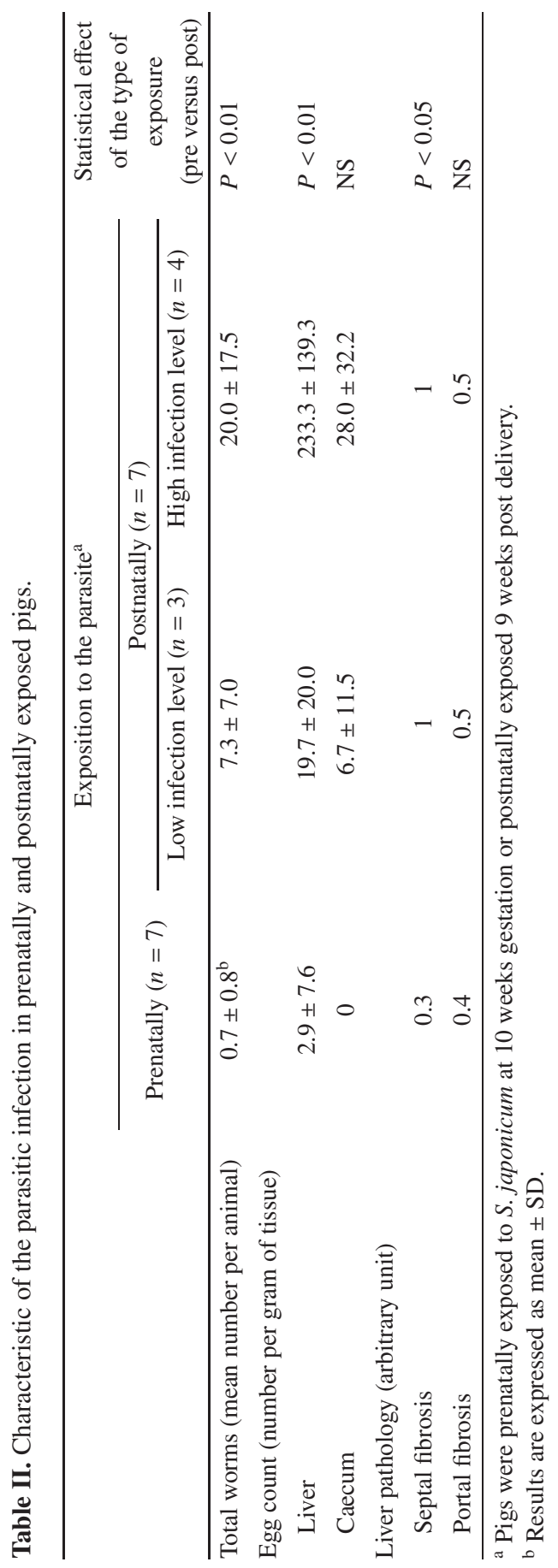




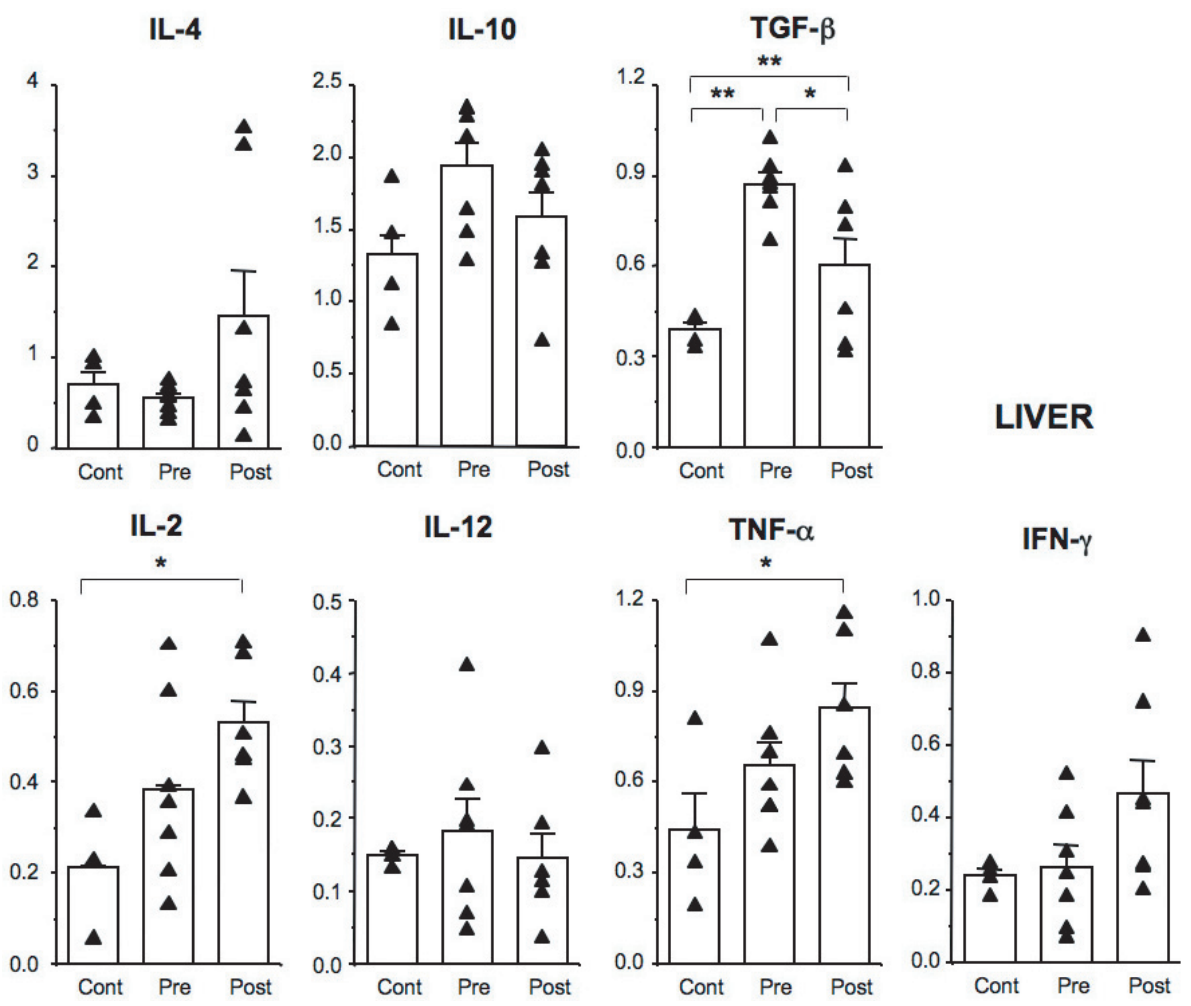

Figure 1. Cytokine mRNA expression levels in liver tissue from pigs prenatally or postnatally exposed to Schistosoma japonicum. Closed triangles represent the individual values and vertical bars the mean $( \pm \mathrm{SD})$ of these results for each group. Comparison of the cytokine levels observed in control, prenatally and postnatally exposed animals, $* P<0.05$ and $* * P<0.01$.

significantly higher than the levels in the control group $(P<0.05)$.

The results obtained could be reflecting differences in infection levels between the prenatally and the postnatally exposed group. In order to investigate this hypothesis, the postnatally exposed group was divided into two subgroups consisting of pigs with lower (3 pigs) or higher infection intensities (4 pigs), and data was re-analysed with respect to these groups. The postnatal subgroup with low infection levels was comparable to the prenatally exposed group regarding worm and egg counts. Levels of cytokine mRNA for each of the postnatally exposed subgroups were then compared to the prenatally exposed group and to the control group. As before, the prenatally exposed group had significantly higher levels of mRNA encoding TGF- $\beta 1$ in the liver compared to the control and both postnatally exposed subgroups $(P<0.05)$. No significant differences were found between the groups regarding TGF- $\beta 1$ levels in the caecum. The above mentioned differences between the postnatal group (7 pigs) and the control group were also observed when comparing each of the postnatal subgroups with the control group. 


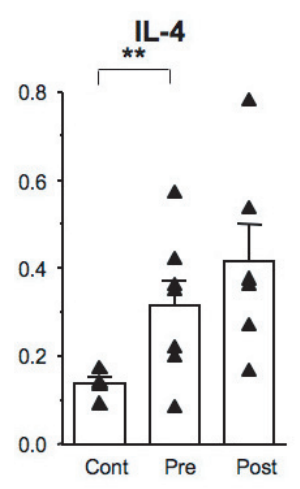

IL-2

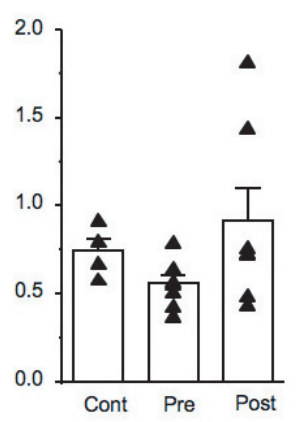

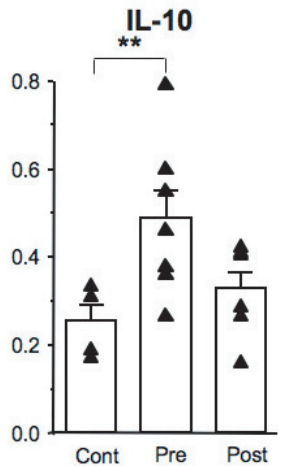

IL-12

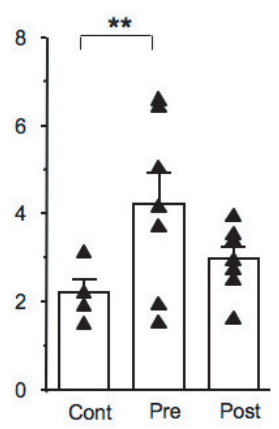

TGF- $\beta$

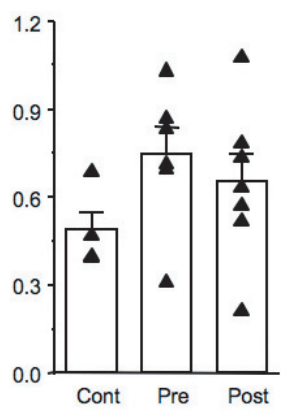

\section{CAECUM}

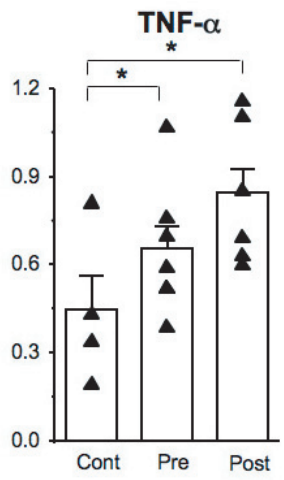

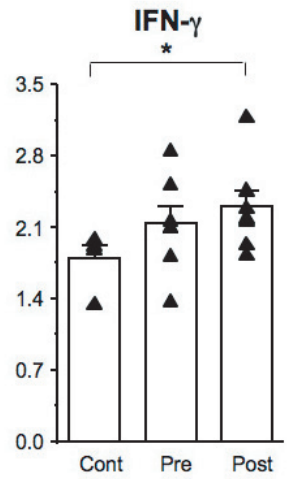

Figure 2. Cytokine mRNA expression levels in caecum tissue from pigs prenatally or postnatally exposed to Schistosoma japonicum. Closed triangles represent the individual values and vertical bars the mean $( \pm \mathrm{SD})$ of these results for each group. Comparison of the cytokine levels observed in control, prenatally and postnatally exposed animals, $* P<0.05$ and $* * P<0.01$.

\section{DISCUSSION}

In line with previous studies on prenatal schistosomiasis in pigs, significantly higher establishment of worms and higher tissue egg counts were seen in the postnatally exposed group compared to the prenatally exposed group, emphasizing that infections obtained through vertical transmission are generally characterised by low infection intensities [18]. Limited fibrosis formation was observed in the prenatal group, and the level of septal fibrosis was significantly higher in the postnatal group.

We employed a semiquantitative RTPCR procedure, in order to investigate the cytokine expression in granulomatous liver and caecum tissue in prenatally and postnatally exposed pigs. Our data indicate that there are differences in the cytokine profiles between prenatally and postnatally exposed pigs, independent of infection intensity when compared to the control group 27 weeks post infection. IL-10 is an antiinflammatory agent, which has been shown to dampen a number of responses, including macrophage cytokine secretion, Th2 cell proliferation, IL-4 induced IgE synthesis and IL-5 production $[3,36,50]$. Our observation that prenatally exposed pigs show high IL-10 levels and low hepatic fibrosis suggests a similar role for IL-10 in pigs. In a number of human schistosomiasis studies, high levels of IL-10 have been 
shown to be associated with reduced susceptibility to infection, and to play a role in antigen-specific suppression [26,29]. TGF$\beta 1$ is also regarded as a potent immunoregulatory cytokine, regulating the differentiation, proliferation and state of activation of a large number of immune cells, thereby modulating both cellular and humoral mediated responses [28]. The prenatally exposed group had significantly higher levels of mRNA encoding TGF- $\beta 1$ in the liver compared to the control and the postnatally exposed group $(P<0.05)$, whereas no significant differences were found between caecum TGF- $\beta 1$ levels within the three groups. Our observation, that TGF$\beta 1 \mathrm{mRNA}$ levels were higher in prenatally exposed pigs, showing less septal fibrosis, suggests that TGF- $\beta 1$ may mediate downregulatory responses beneficial to the prenatally exposed pigs.

In the postnatally exposed pigs, significantly higher levels of TNF- $\alpha$, together with a tendency to higher levels of IL-2 and IL-4, indicate the existence of a dynamic and not yet polarized Th2 response [40]. Apart from being the principal mediator of acute inflammatory responses, TNF- $\alpha$ is important for the induction of fibroblast mitosis [19]. Interestingly, TNF- $\alpha$ treatment has been shown to restore granuloma formation in S. mansoni infected SCID mice, and furthermore to lead to a dosedependent increase in the total number of parasite eggs [1]. Our results suggest that TNF- $\alpha$ may also play a role in hepatic fibrosis development in pigs postnatally infected with $S$. japonicum.

Blockade of IL-2 responses in S. japonicum infected mice, leads to reduced hepatic fibrosis, an effect thought to be caused by the down-regulation of Th2 responses [5]. Moreover, anti-IL-4 treatment of $S$. mansoni or $S$. japonicum infected mice has been shown to result in decreased fibrosis formation and reduced granuloma size $[6,9]$. These results emphasise the importance of a Th2 response in murine schistosome fibrosis and granuloma formation $[38,39]$. Our observations are in line with these results, indicating that high IL-2 and IL-4 responses in postnatally exposed pigs, may mediate fibrosis formation. IFN- $\gamma$ responses have been shown to be prominent in early disease, while downregulated in chronic human schistosome infections $[15,32]$. In our experiment, levels of IFN- $\gamma$ mRNA did not differ between infected and control pigs, but some variation in the expression level of this cytokine was observed.

The cytokine profiles in the caecum displayed similar differences between prenatally or postnatally exposed pigs, as observed for the liver. A high IL-10/IL-4 ratio in prenatally exposed pigs together with high TGF- $\beta 1$ levels seem to dominate, while postnatally exposed pigs show higher expression of IL-2 and IL-4. Intestinal tissue damage, due to toxic products released from developing schistosome eggs, is often combined with secondary bacterial infection [37], which might explain the higher IL-12 and TNF- $\alpha$ levels seen in the caecum of prenatally exposed pigs.

Interleukin (IL)-13 is a key inducer of several type-2 cytokine-dependent pathologies [46]. Recently, this cytokine has been described to regulate tissue remodelling and fibrosis formation in the murine schistosomiasis model and is regarded as a central mediator of chronic infection-induced liver pathology $[46,47]$. At the time of this study, antibody towards porcine IL-13 and porcine IL-13 sequence were not available and hence IL-13 levels could not be determined. In future experiments, however, it will be of interest to characterize the expression pattern of IL-13 in the porcine schistosomiasis model.

In line with a previous study [26], we show that postnatally exposed pigs seem to mount a Th2 like response, with high IL-2 and IL-4 levels locally in lesion sites of the liver and caecum. Th2 responses, 
although related to hepatic fibrosis, seem to be associated with reduced susceptibility and host protection against overt human hepatosplenic disease due to inflammatory responses [25, 30,33]. Indeed, also porcine IL-4 has been shown to play an important role in the regulation of macrophage mediated inflammatory responses [49]. In prenatally exposed pigs, a high IL-10/IL-4 ratio, together with high levels of TGF- $\beta$ seem to dominate, suggesting that these pigs mount a more Th3 like response [16, 43]. Such IL-10 and TGF- $\beta 1$ dominated responses have been shown to dominate and mediate antigen-specific cellular hyporesponsiveness in other chronic human helminth infections $[12,26]$. This indicates that the partial tolerance induced in prenatally exposed pigs [22] might be mediated by antigen-specific hyporesponsiveness, resulting in lower levels of hepatic fibrosis.

\section{ACKNOWLEDGEMENTS}

Special thanks to Ionelia Taranu and Daniela Marin (Laboratory of Pharmacology and Toxicology, INRA, Toulouse, France), to Heidi M. Nielsen (DBL - Institute for Health Research and Development, Denmark) and to Brian Lassen and Pernille Bach (The Royal Veterinary and Agricultural University, Denmark) for technical assistance. Advice on statistical analysis from Henry Madsen was greatly appreciated. This study was financially supported by The Danish National Research Foundation.

\section{REFERENCES}

[1] Amiri P., Locksley R.M., Parslow T.G., Sadick M., Rector E., Ritter D., McKerrow J.H., Tumour necrosis factor alpha restores granulomas and induces parasite egg-laying in schistosome-infected SCID mice, Nature (1992) 356:604-607.

[2] Andrade Z.A., Cheever A.W., Characterization of the murine model of schistosomal hepatic periportal fibrosis, Int. J. Exp. Pathol. (1993) 74:195-202.
[3] Bogdan C., Nathan C., Modulation of macrophage function by transforming growth factor beta, interleukin-4, and interleukin-10, Ann. NY Acad. Sci. (1993) 685:713-739.

[4] Bogh H.O., Willingham A.L., Johansen M.V., Eriksen L., Christensen N.O., Recovery of Schistosoma japonicum from experimentally infected pigs by perfusion of liver and mesenteric veins, Acta Vet. Scand. (1997) 38:147-155.

[5] Cheever A.W., Xu Y., Sher A., Finkelman F.D., Cox T.M., Macedonia J.G., Schistosoma japonicum-infected mice show reduced hepatic fibrosis and eosinophilia and selective inhibition of interleukin-5 secretion by CD4+ cells after treatment with anti-interleukin-2 antibodies, Infect. Immun. (1993) 61:1288-1292.

[6] Cheever A.W., Finkelman F.D., Cox T.M., Anti-interleukin-4 treatment diminishes secretion of Th2 cytokines and inhibits hepatic fibrosis in murine schistosomiasis Japonica, Parasite Immunol. (1995) 17:103-109.

[7] Cheever A.W., Yap G.S., Immunologic basis of disease and disease regulation in schistosomiasis, Chem. Immunol. (1997) 66:159176.

[8] Chen M.G., Schistosoma japonicum and S. japonicum-like infections - Epidemiology, clinical and pathological aspects, in: Jordan P., Webbe G., Sturrock R.F. (Eds.), Human schistosomiasis, CAB International, Oxon, 1993, pp. 242-243.

[9] Chensue S.W., Terebuh P.D., Warmington K.S., Hershey S.D., Evanoff H.L., Kunkel S.L., Higashi G.I., Role of IL-4 and IFN-gamma in Schistosoma mansoni egginduced hypersensitivity granuloma formation. Orchestration, relative contribution, and relationship to macrophage function, $\mathrm{J}$. Immunol. (1992) 148:900-906.

[10] Darwich L., Pié S., Rovira A., Segalés J., Domingo M., Oswald I.P., Mateu E., Cytokine mRNA expression profiles in lymphoid tissues of pigs naturally affected by postweaning multisystemic wasting syndrome, J. Gen. Virol. (2003) 84:2117-2125.

[11] Davies S., Grogan J., Blank R., Lim K., Locksley R., McKerrow J., Modulation of blood fluke development in the liver by hepatic CD4+ lymphocytes, Science (2001) 294:1358-1361.

[12] Doetze A., Satoguina J., Burchard G., Rau T., Loliger C., Fleischer B., Hoerauf A., Antigen-specific cellular hyporesponsiveness in a chronic human helminth infection is 
mediated by $\mathrm{T}(\mathrm{h}) 3 / \mathrm{T}(\mathrm{r}) 1$-type cytokines IL10 and transforming growth factor-beta but not by a T(h)1 to T(h) 2 shift, Int. Immunol. (2000) 12:623-630.

[13] Fallon P.G., Immunopathology of schistosomiasis: a cautionary tale of mice and men, Immunol. Today (2000) 21:29-35.

[14] Fallon P.G., Richardson E.J., McKenzie G.J., McKenzie A.N., Schistosome infection of transgenic mice defines distinct and contrasting pathogenic roles for IL-4 and IL-13: IL13 is a profibrotic agent, J. Immunol. (2000) 164:2585-2591.

[15] Grogan J.L., Kremsner P.G., Deelder A.M., Yazdanbakhsh M., Antigen-specific proliferation and interferon-gamma and interleukin-5 production are down-regulated during Schistosoma haematobium infection, J. Infect. Dis. (1998) 177:1433-1437.

[16] Groux H., O’Garra A., Bigler M., Rouleau M., Antonenko S., de Vries J.E., Roncarolo M.G., A CD4+ T-cell subset inhibits antigenspecific T-cell responses and prevents colitis, Nature (1997) 389:737-742.

[17] Hurst M.H., Shi Y.E., Lindberg R., Pathology and course of natural Schistosoma japonicum infection in pigs: results of a field study in Hubei province, China, Ann. Trop. Med. Parasitol. (2000) 94:461-477.

[18] Iburg T., Balemba O.B., Danizer V., Leifsson P.S., Johansen M.V., Pathogenesis of congenital infection with Schistosoma japonicum in pigs, J. Parasitol. (2002) 88:10211024.

[19] Jaattela M., Biologic activities and mechanisms of action of tumor necrosis factoralpha/ cachectin, Lab. Invest. (1991) 64:724742.

[20] Johansen M.V., Effect of praziquantel treatment on experimental porcine Schistosoma japonicum infection, Parasitology (1998) 116:519-524.

[21] Johansen M.V., Bogh H.O., Nansen P., Christensen N.O., Schistosoma japonicum infection in the pig as a model for human schistosomiasis Japonica, Acta Trop. (2000) 76:85-99.

[22] Johansen M.V., Iburg T., Bogh H.O., Christensen N.O., Postnatal challenge infections of congenitally Schistosoma japonicum-infected piglets, J. Parasitol. (2001) 87:813-815.

[23] Johansen M.V., Ørnbjerg N., Prenatal Schistosoma japonicum infection in piglets: effect of repeated exposure of the dams on treatment efficacy and susceptibility to challenge infections, J. Parasitol. (2004) 90:392-396.

[24] Kaplan M., Whitfield J., Boros D., Grusby M., Th2 cells are required for the Schistosoma mansoni egg-induced granulomatous response, J. Immunol. (1998) 160:1850-1856.

[25] Karanja D.M., Hightower A.W., Colley D.G., Mwinzi P.N., Galil K., Andove J., Secor W.E., Resistance to reinfection with Schistosoma mansoni in occupationally exposed adults and effect of HIV-1 co-infection on susceptibility to schistosomiasis: a longitudinal study, Lancet (2002) 360:592-596.

[26] King C.L., Medhat A., Malhotra I., Nafeh M., Helmy A., Khaudary J., Ibrahim S., El Sherbiny M., Zaky S., Stupi R.J., Brustoski K., Shehata M., Shata T., Cytokine control of parasite-specific anergy in human urinary schistosomiasis. IL-10 modulates lymphocyte reactivity, J. Immunol. (1996) 156:4715-4721.

[27] King C., Dickman K., Tisch D., Reassessment of the cost of chronic helmintic infection: a meta-analysis of disability-related outcomes in endemic schistosomiasis, Lancet (2005) 365:15611569.

[28] Letterio J.L., Roberts A.B., TGF-b: a critical modulator of immune cell function, Clin. Immunol. Immunopathol. (1997) 84:244 250 .

[29] McManus D.P., Ross A.G., Sleigh A.C., Williams G.M., Yang W., Li Y.S., Li Y., Acosta L., Waine G.J., Production of interleukin-10 by peripheral blood mononuclear cells from residents of a marshland area in China endemic for Schistosoma japonicum, Parasitol. Int. (1999) 48:169-177.

[30] Medhat A., Shehata M., Bucci K., Mohamed S., Dief A.D., Badary S., Galal H., Nafeh M., King C.L., Increased interleukin-4 and interleukin-5 production in response to Schistosoma haematobium adult worm antigens correlates with lack of reinfection after treatment, J. Infect. Dis. (1998) 178:512519.

[31] Moloney N.A., Webbe G., A rapid method for the infection of laboratory mice with Schistosoma japonicum, Trans. R. Soc. Trop. Med. Hyg. (1982) 76:200-203.

[32] Montenegro S.M., Miranda P., Mahanty S., Abath F.G., Teixeira K.M., Coutinho E.M., Brinkman J., Goncalves I., Domingues L.A., Domingues A.L., Sher A., Wynn T.A., Cytokine production in acute versus chronic 
human schistosomiasis mansoni: the crossregulatory role of interferon-gamma and interleukin-10 in the responses of peripheral blood mononuclear cells and splenocytes to parasite antigens, J. Infect. Dis. (1999) 179:1502-1514.

[33] Mwatha J.K., Kimani G., Kamau T., Mbugua G.G., Ouma J.H., Mumo J., Fulford A.J., Jones F.M., Butterworth A.E., Roberts M.B., Dunne D.W., High levels of TNF, soluble TNF receptors, soluble ICAM-1, and IFN-gamma, but low levels of IL-5, are associated with hepatosplenic disease in human schistosomiasis mansoni, J. Immunol. (1998) 160:1992-1999.

[34] Oswald I.P., Dozois C.M., Barlagne R., Fournout S., Johansen M.V., Bogh H.O., Cytokine mRNA expression in pigs infected with Schistosoma japonicum, Parasitology (2001) 122:299-307.

[35] Pié S., Lallès J.P., Blazy F., Laffitte J., Sève B., Oswald I.P., Weaning is associated with an up-regulation of expression of inflammatory cytokines in the intestine of piglets, $\mathrm{J}$. Nutr. (2004) 134:641-647.

[36] Punnonen J., Malefyt de Waal R., van Vlasselaer P., Gauchat J.F., de Vries J.E., IL-10 and viral IL-10 prevent IL-4-induced IgE synthesis by inhibiting the accessory cell function of monocytes, J. Immunol. (1993) 151:1280-1209.

[37] Ross A., Sleigh A., Li Y., Davis G., Williams G., Jiang Z., Feng Z., McManus D., Schistosomiasis in the People's Republic of China: prospects and challenges for the 21st Century, Clin. Microbiol. Rev. (2001) 14:270-295.

[38] Rumbley C.A., Zekavat S.A., Sugaya H., Perrin P.J., Ramadan M.A., Phillips S.M., The schistosome granuloma: characterization of lymphocyte migration, activation, and cytokine production, J. Immunol. (1998) 161:4129-4137.

[39] Rumbley C.A., Sugaya H., Zekavat S.A., El Refaei M., Perrin P.J., Phillips S.M., Activated eosinophils are the major Source of Th2-associated cytokines in the schistosome granuloma, J. Immunol. (1999) 162:1003-1009.

[40] Stadecker M.J., The regulatory role of the antigen-presenting cell in the development of hepatic immunopathology during infection with Schistosoma mansoni, Pathobiology (1999) 67:269-272.

[41] Techau M.E., Johansen M.V., Lind P., Ornbjerg N., The effect of colostrum on pigs pre-natally or post-natally exposed to Schistosoma japonicum, Parasitology (2004) 129:597-604.

[42] Vennervald B., Dunne D., Morbidity in schistosomiasis: an update, Curr. Opin. Infect. Dis. (2004) 5:439-447.

[43] Weiner H.L., Oral tolerance: immune mechanisms and treatment of autoimmune diseases, Immunol. Today (1997) 18:335-343.

[44] Willingham A.L., Bogh H.O., Vennervald B.J., Johansen M.V., Eriksen L., Christensen N.O., Nansen P., Worm establishment and egg production of Schistosoma japonicum in pigs infected by percutaneous methods or intramuscular injection, Vet. Parasitol. (1996) 61:157-163.

[45] Willingham A.L., Johansen M.V., Bogh H.O., Ito A., Andreassen J., Lindberg R., Christensen N.O., Nansen P., Congenital transmission of Schistosoma japonicum in pigs, Am. J. Trop. Med. Hyg. (1999) 60:311312.

[46] Wynn T.A., IL-13 effector functions, Annu. Rev. Immunol. (2003) 21:425-456.

[47] Wynn T.A., Thompson R.W., Cheever A.W., Mentink-Kane M.M., Immunopathogenesis of schistosomiasis, Immunol. Rev. (2004) 201:156-167.

[48] Zhang Z., Wu H., Chen S., Hu L., Xie Z., Qiu Y., Su C., Cao J.P., Wu Y., Zhang S., Wu G., Association between IgE antibody against soluble egg antigen and resistance to reinfection with Schistosoma japonicum, Trans. R. Soc. Trop. Med. Hyg. (1997) 91:606-608.

[49] Zhou Y., Lin G., Baarsch M.J., Scamurra R.W., Murtaugh M.P., Interleukin-4 suppresses inflammatory cytokine gene transcription in porcine macrophages, J. Leukoc. Biol. (1994) 56:507-513.

[50] Zuany-Amorim C., Creminon C., Nevers M.C., Nahori M.A., Vargaftig B.B., Pretolani M., Modulation by IL-10 of antigen-induced IL-5 generation, and CD4+ T lymphocyte and eosinophil infiltration into the mouse peritoneal cavity, J. Immunol. (1996) 157:377-384. 